\title{
Perceptions of Patients with Xerostomia about Quality of Life, General and Oral Health: A Qualitative Study
}

\author{
Karina Ramírez-Sepúlveda ${ }^{1}$, Andrés Murillo-Pedrozo ${ }^{1}$, Daniela Zuluaga-Villegas ${ }^{1}$, Kristhel Vasco-Grajales ${ }^{1}$, \\ Adriana Posada-López ${ }^{1} \&$ Andrés A. Agudelo-Suárez ${ }^{1}$ \\ ${ }^{1}$ Faculty of Dentistry. University of Antioquia. Medellín, Colombia \\ Correspondence: Andrés A. Agudelo-Suárez; Faculty of Dentistry, University of Antioquia, Calle $70 \mathrm{~N}^{\circ} 52-21$. \\ Medellín, Colombia. Tel: 57-42-196-741; Fax: 57-42-196-700. E-mail: oleduga@gmail.com; \\ alonso.agudelo@udea.edu.co
}

Received: February 3, 2016 Accepted: March 11, 2016 Online Published: March 31, 2016

doi:10.5539/gjhs.v8n11p257 URL: http://dx.doi.org/10.5539/gjhs.v8n11p257

\begin{abstract}
Introduction: We aim to explore the perceptions about quality of life and its relationship with general and oral health of adults suffering from Xerostomia

Methods: A qualitative and exploratory study was conducted from an ethnographic perspective. 22 semi-structured in-depth interviews and one focus group were carried out. Patients were contacted through different institutions and by means of snowball sampling. Furthermore, socio-demographic information was collected and a content narrative analysis was conducted identifying significant text fragments and generating codes and categories.

Results: 6 categories from participants' discourses were identified: 1) Knowledge about general, oral health and Xerostomia; 2) Determinants of access to health services: access barriers are reflected by poor attention and medical opportunity in appointments, misguided diagnosis and treatments, and difficulties obtaining medications; 3) Definitions of quality of life, health and oral health; 4) Social support and relationships: social support is as perceived by families, institutions and social networks enabling them to meet their health goals and the consequences of these; 5) Practice to overcome dry mouth: Several alternative methods were used when medicines are not a satisfactory solution for each individual; 6) Future aspirations: in some cases, a significant number of the participants expressed fear when thinking about the future, and discourses directly relate with their families. In some cases they expressed not to think about the future and "live and enjoy".
\end{abstract}

Conclusions: Xerostomia affects the quality of life not only from individual systemic conditions, but also through determinants from the social context and the health system.

Keywords: Quality of Life, oral health, Xerostomia, self-perception, qualitative research

\section{Introduction}

Saliva is a fluid involved in basic functions such as swallowing, tasting, phonation and speech (Ibáñez, López, \& Piña, 2009; Loyo Molina, Balda Zavarce, González Blanco, Solórzano Peláez, \& González, 1999). As an essential component for the maintenance of oral health $(\mathrm{OH})$ (Kaluzny, Wierzbicka, Nogala, Milecki, \& Kopec, 2014; Loyo Molina et al., 1999), it contributes to microbial control of the oral cavity. Saliva secretion is influenced by factors such as age, sex, size of the glands, emotionality, degree of hydration and habits (Kaluzny et al., 2014; Loyo Molina et al., 1999). Dry mouth is caused by a poor flow of saliva. Since draught irritates the soft tissues in the mouth, it can create inflammation making individuals are more susceptible to infection (Loyo Molina et al., 1999). Hyposalivation in most cases takes place silently and symptoms are not perceived until this situation is advanced. This is the time at which the Xerostomia appears as the subjective perception of dry mouth. Patients with Xerostomia may have difficulty speaking, eating and swallowing. Some patients complain of halitosis, chronic burning sensation, altered taste and intolerance to spicy food (Anil et al., 2016; Bascones et al., 2007; Kaluzny et al., 2014). In general terms, the quality of life of patients with Xerostomia could be affected (Bascones et al., 2007; Enoki et al., 2014; Ikebe et al., 2007).

Xerostomia affects one in four individuals. This indicator increases in people older than 50-60 years (Anil et al., 2016; Bascones et al., 2007). Although until recently it was believed that Xerostomia was exclusively of older 
people, there are studies that found a prevalence of this symptom in people under 20 years of age (Bascones et al., 2007). This condition is observed in greater proportion in females (Benn, Broadbent, \& Thomson, 2015; Lee, Lee, Kim, \& Kho, 2014), mainly due to hormonal changes associated with pregnancy or menopause (Bascones et al., 2007). In general terms, according to different studies, the prevalence of Xerostomia is variable depending on the type of study, target population and other factors analysed conjointly (Al-Dwairi \& Lynch, 2014; Benn et al., 2014; Hahnel, Schwarz, Zeman, Schafer, \& Behr, 2014; Lee et al., 2014; Liu, Dion, Jurasic, Gibson, \& Jones, 2012).

An important number of related studies has focused on analyzing the prevalence of Xerostomia and its related factors (Lee et al., 2014). They were mainly conducted in elders through epidemiological research (Al-Dwairi \& Lynch, 2014; Hahnel et al., 2014; Liu et al., 2012). Since the basis of the treatment for this condition is palliative, other studies have focused on assessing the more effective therapeutic mechanisms for patients (Ami \& Wolff, 2010; Chapa, Garza, Garza, \& Martínez, 2012; Coimbra, 2009; Oh, Lee, Kim, \& Kho, 2008; Strietzel et al., 2007). As a consequence, it is important to pay attention to the opinions and perceptions of patients about this disease as well as some social and individual factors that could be determinant.

The study of quality of life and its relationship to health involves both the subjective perception of the individual life conditions and personal satisfaction as well as the determinants that impact on the physical, mental and psychosocial health situation (Misrachi \& Espinoza, 2005). The majority of studies assessing health-related quality of life have included epidemiological instruments that measure physical and emotional health and the ability to perform usual activities (Misrachi \& Espinoza, 2005). In case of oral health-related quality of life, other surveys measure pain, functional limitations and psychological, emotional and social disabilities associated with the mouth (Allen, 2003).

In case of patients suffering from Xerostomia, studies aimed to characterize the effect of oral health on quality of life and relationships among self-reported oral health, systemic health and objective clinical measures of health in different kinds of patients with systemic (e.g. Sjögren syndrome) or specific local conditions (Enoki et al., 2014; Hahnel et al., 2014; Ikebe et al., 2007; C. M. Stewart, Berg, Cha, \& Reeves, 2008). Nevertheless, qualitative research on this topic is scarce. This kind of research could be considered as an opportunity for addressing future challenges in dentistry (Masood, Masood, \& Newton, 2010; K. Stewart, Gill, Chadwick, \& Treasure, 2008), by studying the social construction of the illness, the characteristics related with quality of life and to describe the determinants of health inequalities in individuals suffering this disease.

In this context, we aim to explore the perceptions on quality of life and its relationship with general and oral health in adults suffering from Xerostomia.

\section{Methods}

\subsection{Study Design and Participants}

A qualitative, descriptive and comprehensive study was conducted, following an ethnographic perspective and by means of in-depth interviews (ID). This approach pretends to reveal the meanings of patient's speeches in day-to-day social contexts and to interpret them within a cultural system. The sample design for the IDs was theoretical, meaning that a variety of participants were selected who could provide insights from different perspectives about the research question. The final sample was 22 people, and defined by saturation of information, when the non-contribution of new data relating to the study aims was observed. Participation criteria were considered voluntary in patients suffering from Xerostomia, older than 18 years of age and able to adequately answer the interview. The eligibility of participants was based on criteria for diagnosis of Xerostomia previously established in the literature (Villa, Connell, \& Abati, 2015).

\subsection{Data Collection}

Fieldwork took place in Medellín (Colombia) between December 2013 and August 2014. Researchers contacted individuals through different strategies: Organizations that offer support to patients with Xerostomia and other conditions (Rheumatism), Patients attending the Faculty of Dentistry at University of Antioquia, and by using the snowball method.

A semi-structured script was used and the topics were based on previous scientific and grey literature about quality of life (Misrachi \& Espinoza, 2005). The interviewer went into great depth about the important contents in terms of the study aims and, through free discussion allowed new analysis categories to emerge. The issues tackled are shown in Table 1. Sociodemographic information was gathered about age, sex, socioeconomic stratification (according to the neighborhood of residence), marital status, social security (health), education and occupation. A general demographic overview of the participants is presented in Table 2. The IDs were 
complemented with participant observation for at least one member of the research team who took informative notes about the development of the IDs and observed the attitude of the interviewees. The interviews lasted between 20 and 30 minutes and were digitally recorded and transcribed verbatim. Interviews were conducted by four of the authors (KR, KV, AM, DZ), previously trained in qualitative research techniques for the other two members of the research team (AP, AA) who have experience in this kind of methodological approaches.

Table 1. Content of the semi-structured script used in interviews with participants $(\mathrm{n}=22)^{*}$

THEME/ISSUE QUESTIONS

1. Assessment of their oral/general health status and determinants or factors that affect this assessment.
- How would you rate your health in general? Why?

- What situations do you think could affect your overall health? Why?

- How would you rate your oral health? Why?

- What situations do you think could affect your oral health? Why?

- $\quad$ For you, what is quality of life?

2. Defining quality of life, health-related quality of life and oral-health related quality of life: Assessment of the quality of life in terms of positive or negative feelings

- How would you rate your quality of life in your overall health and in your mouth? Why?

- How long do you have Xerostomia?

- Do you know why do you have this condition?

- What aspects of your life have been affected for this condition? What do you think are the most important?

- Has this condition represented some kind of disability? (Eating, talking, his emotional life, work, etc.) Why?

- Have you ever received any treatment? Where?

3. Socio-environmental factors: social support, resources, networks, social security, functional role and risk factors

- Do you have health insurance? Have you been treated there?

- Do you have economic resources for private treatment?

- Have you ever been in a support group? Tell me about your experience there

- Do you have any other disease caused for the Xerostomia?

$\begin{array}{lr}\text { 4. Feelings: } & \text { vulnerability, } \\ \text { dependency, } & \text { insecurity, }\end{array}$

loneliness, self-esteem, changing

- Any circumstance related to Xerostomia has affected their emotional state? roles, hobbies

5. Opinion on health services - How would you rate the care you have found by your entity providing health accessibility services in connection with Xerostomia?

6. General situation of people suffering Xerostomia in Medellin, in the neighbourhood, in Colombia (Contextcomparability).

- Do you meet someone else who suffers Xerostomia? Do you know his/her opinion on this?

- What do you identify with others who have Xerostomia with? What is different?

*This is a general script but during the interview could generate new questions of topics according to the participants' experiences 
Table 2. Sociodemographic characteristics of participants $(n=22)$

\begin{tabular}{|c|c|}
\hline Characteristics & $\mathbf{n}$ \\
\hline \multicolumn{2}{|l|}{ Age } \\
\hline Mean (Range) & $60(39-77)$ \\
\hline \multicolumn{2}{|l|}{$\operatorname{Sex}$} \\
\hline Male & 1 \\
\hline Female & 21 \\
\hline \multicolumn{2}{|c|}{ Socioeconomic status* } \\
\hline Low & 6 \\
\hline Middle & 15 \\
\hline High & 1 \\
\hline \multicolumn{2}{|l|}{ Marital status } \\
\hline Single & 6 \\
\hline Married & 7 \\
\hline Marital union & 2 \\
\hline Widow & 4 \\
\hline Divorced & 3 \\
\hline \multicolumn{2}{|c|}{ Social security in health (insurance regime) $* * *$} \\
\hline Subsidized & 2 \\
\hline Contributory & 17 \\
\hline Prepaid health care & 1 \\
\hline Special insurance & 2 \\
\hline \multicolumn{2}{|l|}{ Education } \\
\hline$<=$ Primary & 4 \\
\hline Secondary & 8 \\
\hline University & 10 \\
\hline \multicolumn{2}{|l|}{ Occupation } \\
\hline Housewife & 11 \\
\hline University professor & 1 \\
\hline Musician & 1 \\
\hline Retired & 9 \\
\hline Total & 22 \\
\hline
\end{tabular}

* According to the neighborhood of residence

** The health system in Colombia is constituted two insurance schemes that aim to cover the entire population: the contributory regime (RC), which serves people with payment capacity (formal workers) and the subsidized regime (RS) for people in a state of social vulnerability. Prepaid health care is a special type of insurance with additional benefits for RC. Special insurance is constituted for people in armed forces and certain types of public enterprises (education, oil companies, etc.)

At the end of the fieldwork, a focus group of 10 participants previously in-depth interviewed was organized in order to share their experiences about the disease which served as guarantee of the saturation of the information collected in the interviews. In addition, the research team prepared an educative conference about preventive and health promotion strategies for Xerostomia as a strategy of social return for these participants. 


\subsection{Data Analysis}

An initial data reading was carried out in order to check the quality of the transcriptions. Narrative content analysis was conducted identifying significant pieces of text and trends of information found in the participants' discourse. Initially, manual analysis was performed. Subsequently, transcribed data were imported into the qualitative analysis software Atlas.Ti 6.0. The text fragments were labelled in codes and then grouped into categories. Initial and emerging analysis categories were developed by means of a conceptual framework summarizing the information collected.

Data analysis were conducted by four of the authors (KR, KV, AM, DZ), who examined and compared their analyses, and was supervised for the other two members of the research team (AP, AA). The extracts of the discourses in the text were chosen from their representativeness and are presented using a label indicating the source of data.

\subsection{Ethics}

Since participation was voluntary all respondents gave written informed consent. Confidentiality is guaranteed. This study was conducted in accordance with International and Colombian regulations. Ethical Committee at the Faculty of Dentistry at University of Antioquia approved the study (Act $\mathrm{N}^{\circ} 2-2016$ ).

\section{Results}

Figure 1 shows Conceptual framework followed for the analysis of the interviews (topic, categories, and codes). After their analysis, five main categories emerged from participants' discourses. These categories are derived from one main topic: Determinants of quality of life, general and oral health in patients affected by Xerostomia. Additionally, a cross category called future expectations was obtained. The categories are discussed as follows:

\subsection{Knowledge about Health and Xerostomia}

When asked about general health, most respondents expressed to have clear knowledge and awareness of diseases affecting them, mainly because of the information obtained by health professionals who care for them and their experience with the disease (Table 3: 1a).

With respect to oral health and Xerostomia, most of the respondents agree that they are aware they have a dry mouth and this condition is confirmed by health professionals. Interviewees know their characteristics, consequences and determinants. However, other group of respondents expressed ignorance about the causes of the disease (Table 3: 1b, 1c).

\subsection{Determinants of Health Services Accessibility}

An attitude of complacency or adaptation to services used was expressed in many participants interviewed. This situation is explained because although these services are not the best and many obstacles and barriers to access health care are present, they related not have another alternative and so they need to accept the conditions imposed by the health system (Table 3: 2a, 2b, 2c).

Based on poor attention and opportunity in attention, misdiagnosis and misguided treatments, difficulties obtaining medications and little information given to patients, another point of discontent may be noted (Table 3: $2 \mathrm{~d}, 2 \mathrm{e}, 2 \mathrm{f})$. In contrast, a much smaller group of respondents expressed their contentment with the care received. This situation responds to health insurance companies that provide broader benefits to patients who received adequate treatments (Table $3: 2 \mathrm{~g}, 2 \mathrm{~h}$ ).

Another important common aspect among the majority of respondents was related to access to medication for the treatment of dry mouth: Pilocarpine, Salagen and other medicines. In order to have access to them they had to impose legal resources (Table 3: 2i). 


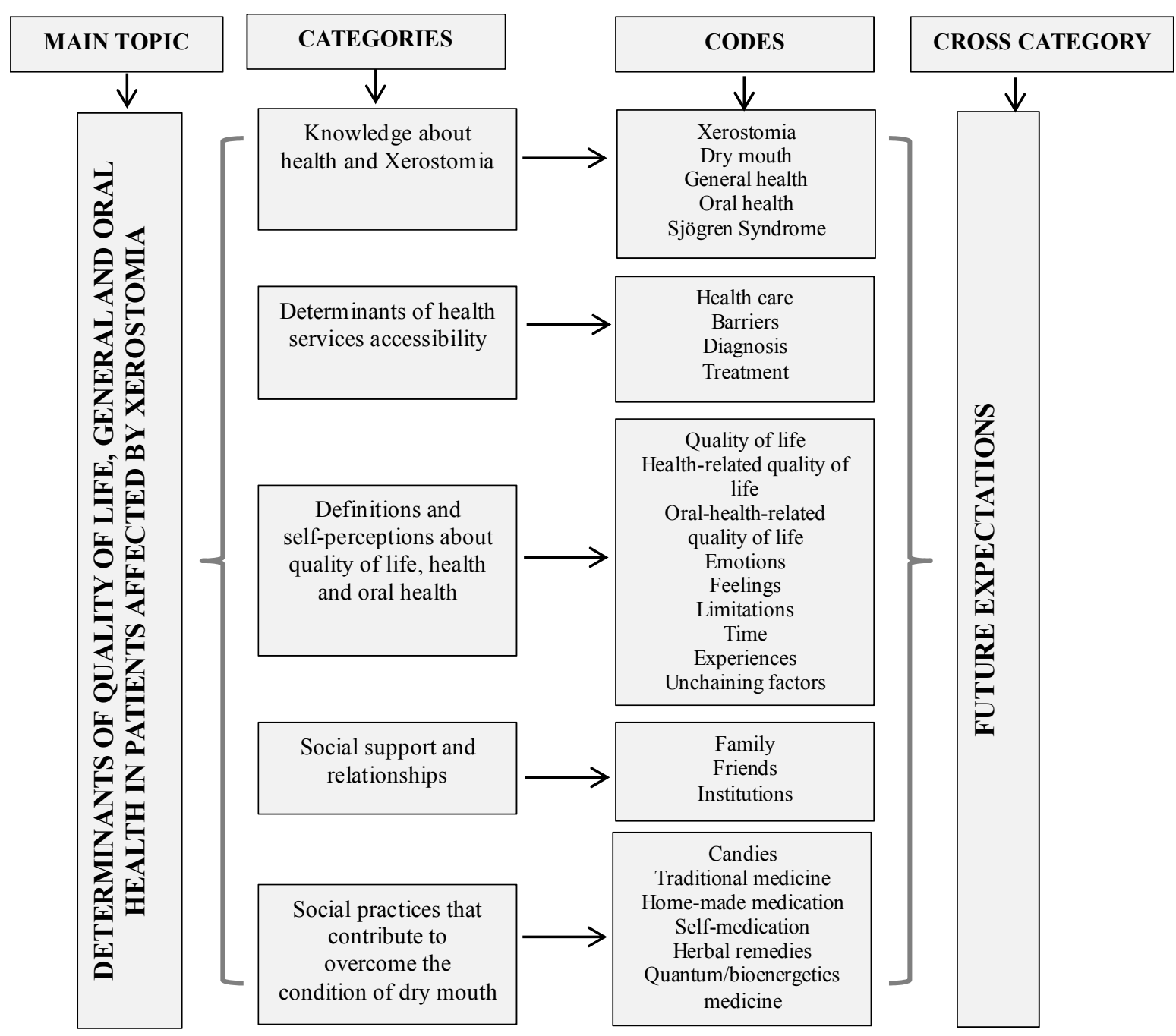

Figure 1. Conceptual framework followed for the analysis of the interviews.

\subsection{Definitions and Self-Perceptions about Quality of Life, Health and Oral Health}

Participants expressed several definitions about quality of life (QL). This concept is related to wellbeing and carrying out the daily activities normally. It is also expressed as the enjoyment of the various aspects considered as important in life. The role of family and interpersonal relationships as fundamental pillars for proper QL was also recognized. Health-related quality of life (HQL) is perceived as the absence of disease and no signs of pain (Table 3: 3a, 3b, 3c).

Throughout the interviews the participants made a self-assessment of their current QL. Some participants expressed to have a good QL in despite of their health problems and systemic conditions (Table 3: 3d, 3e).

Individuals perceived QL as fair or poor for reasons related with mobility problems due to additional health problems, or associated with having symptoms that go beyond Xerostomia and represent signs of pain. Moreover, the fact of being poly medicated for various diseases is an aspect influencing poor QL (Table 3: 3f, 3g)

Similarly, interviewees expressed different valuations of their own health situation. One group called themselves as patients with good health thanks to their ability to assimilate and learn to with the disease. Individuals who perceived their general health as fair do so because of some limitation presented by their illness, in case of mobility or when they have lost the sense of smell. Lastly, respondents expressed overall health as poor when several underlying diseases such as congenital disorders or syndromes affected them or when they have other untreated symptoms such as manifestations of ear dryness (Table $3: 3 \mathrm{~h}, 3 \mathrm{i}, 3 \mathrm{j}$ ).

In relation to oral health $(\mathrm{OH})$, the respondents' discourses have linked oral status to the oral hygiene and oral health care they had, and the response to the body to such care. Interviewees rated their $\mathrm{OH}$ as good when they 
gave comprehensive care to the mouth. A regular self-perceived $\mathrm{OH}$ caused by the lack of moisture in the mouth. In some cases, patients need to use lubricants which are not tolerated by all due to its viscosity. Another reason to consider a fair $\mathrm{OH}$ is the feeling of deterioration of oral structures despite their dental hygiene. Finally, some interviewees considered poor $\mathrm{OH}$ when their condition represented teeth loss, frequent occurrence of dental cavities, calculus and periodontal disease, as well as the inability to speak due to Xerostomia (Table $3: 3 \mathrm{k}, 31,3 \mathrm{~m}$, $3 n)$.

\subsection{Social Support and Relationships}

Interviewees expressed to receive great support from their families, allowing them to face their disease and its consequences in the most appropriate manner (Table 3: 4a, 4b, 4c).

In respect to institutional social support most individuals have received it from foundations or institutions where they have been treated. They have participated as volunteers in research focused on dry mouth. These institutions have provided them with medicines. They have received lectures about their condition, which have been very important to respondents because it allows them to have more knowledge about their situation and how to get an acceptable $\mathrm{OH}$ (Table 3: 4d).

Regarding interpersonal relationships with friends or people with the same condition, respondents expressed to know these support groups, and highlighted the importance of sharing their experiences about the disease within these groups so they can make comparisons in terms of similarities and differences between them. Nevertheless, other responses of interviewees had in common not belonging to support groups because of the emotional burden when they know about the health of others and they could eventually be reflected on them (Table 3: 4e).

\subsection{Social Practices That Contribute to Overcome Dry Mouth}

The treatment for different patients with Sjögren syndrome or Xerostomia is mainly focused on mitigating the symptoms with local palliative measures. In other cases, there are medications directed to the systemic condition of the disease or autoimmune symptoms. The treatment is not completely effective and scientifically well known as curative. Nevertheless, individuals have developed strategies allowing them to keep the mouth moist in order to perform properly and comfortably in their everyday life (Table 3: 5a, 5b, 5c, 5d).

It is interesting to recognize participants who have decided to approach the Xerostomia from an alternative point a view. Individuals expressed the use of measures that are not specific for this condition but that helped with their personal problems and to overcome the major symptoms of the disease (Table 3: 5e, 5f).

Table 3. Verbatim interview extracts form participants' discourses $(n=22)$

CATEGORIES VERBATIM EXTRACTS*

1. Knowledge about health and Xerostomia

a) “...Say autoimmune pathologies, Sjögren Syndrome, hair loss, psoriasis and all related with these pathologies: endocrinal diseases, rheumatic diseases..." [1-10]

b) “...it is an autoimmune condition were defenses attack the body. Exocrine glands attack us generating liquids, non-existent tears, sweat, lubrication which, at this point in life, is also over. An autoimmune thing..." [I-3]

c) “...No, I don't know because no one in my family has or has had this disease. The doctor said I just got it..." [I-8]

2. Determinants of health services accessibility a) “...One has to adapt to the problems imposed by [private service providers] EPS. It is a personal adaptation which is required..." [I-4]

b) “...[State Service provider] SISBEN, has helped me a lot and the legal mechanisms [tutela in Spanish] ... I am very grateful for it...” [I-8]

c) “...One has to be patient. Nowadays who work for a [private service provider] EPS have limited time and some lists of patients to see, many things to attend to and it's not enough" [I-13]

d) “...It seems a pilgrimage now. It seems you are begging for money”[I-9]

e) “...Access to health services is very simple. Precision in diagnosis is nonexistent. After about 14 years of going to general practitioners and specialists to always get the same inadequate treatments because they had not identified the pathology... " [1-10]

f) “...Medicine sometimes does not reach me on time so I last months, say one month, 
without treatment..." [I-14]

g) “...Timely, I call and they see to me or send me to the ER immediately. I have the best services in Medellin because we are a part of the population that should be ashamed of all the good it has..." [I-2]

h) “...I have access to any type of medicine. Why? Because I need it. There is a very ethical medical care..." [I-2]

i) “...I had to take legal action for a medicine that could not be suspended..." [I-5]

3. Definitions and self-perceptions about quality of life, health and oral health a) "To me, quality of life is the enjoyment of things in life, hmm, economic cultural, social and biological conditions that allow me, let's say, my health, true... that is for me the definition of quality of life." [I-2]

b) "At least to spend days with fewer pains, that you can stand up, do some of the things you used to, that you can serve the people around you, and enjoy days, things and family without pain present" [I-9]

c) "For me quality of life is to be able to work without a problem or pain. In other words, healthy, it is most important." [I-13]

d) "Given my age and my chronic condition, Schrögen and my heart affected and a neurologist, I feel quality of life..." [I-3]

e) "As I said, given what is normal at my age, I have quality of life, I am active, and I like to be among people..." [I-3]

f) "In general... quality of life is bad, bad. On the one hand this disease has many dry parts so I get many infections in my mouth as well as my skin, and pain is constant. In the mouth one gets cavities and has problems in the nerves. It is a painful disease that makes things come up at different times." [I-15]

g) "Very worn down, highly medicated and I hope one day I can stop the medicines and have a better quality of life." [I-16]

h) "Well, I kind of brainwashed myself if I have a disease I am not going to be defined by it. I do what I have to also because I suffer from rheumatism and Sjögren syndrome" [I-4]

i) "Not too good" ... "the dryness is tough. I feel it in my nose. I have lost about $80 \%$ of smell..." [I-3]

j) "What can I say... it is not good not bad. Thank God I can walk, even if it hurts, I have many limitations to stand and everything, so... not good." [I-11]

k) "No, my oral health has not been compromised because of the severe care I give my mouth" [I-2]

l) "It's been a constant vigilance of my mouth so I try to go every six months to the dentist even if there aren't any other problems" [I-4]

m) "Fairly" "Because I am always coming to the dentist and he is always saying that it needs better care, it is very worn down... I floss, brush and everything and I don't know” [I-13]

n) "Bad. At any moment and when I least expect it Bum, a tooth out. Since I take so much calcium, there are stones. Every so often they have to take a tooth out or anything." [I-6]

\footnotetext{
4. Social support and relationships
}

a) “...because I have a family who supports me greatly and quality of life is within you and in the family..." [E5]

b) "Everyone is making sure that I bring water." [I-7]

c) “...I reply completely on my husband ... with my husband who is terrific" [ I-6]

d) "Yes, FUNDARE [name of the institution] and the Center for Biological research [name of the institution] all the family was tested. That is located in Robledo [place], with Dr. [last name]. Then they tested us, one as a patient and the family. 
They went to our house and if one reached or passed the limit then they provided medicine. Apparently I didn't reach the limit of this disease whereas other patients have. [I-13]

e) "They say it is horrible because one is used to have the mouth moist to be able to speak. That is like, like oil for the tongue to talk and communicate adequately with people." [I-6]

\section{Social practices that contribute to overcome dry mouth}

a) “...I keep under my mouth one or two bits of cardamom so that makes my glands to produce saliva and that keeps the mouth moist..." [I-3]

b) “...I put a candy in my mouth..." [I-4]

c) “...I feel the need to apply more, especially when I am speaking; I keep sugar free gum though. It hydrates me ..." [I-8]

d) "... On oral health the doctor tried fresh cool because I have been taking pilocarpina day and night to help me salivate. Dry mouth was maddening and it made me chock so while they tried to decipher what I had I carried around a bottle of water or a piece of plastic. People used to laugh a lot because they said: I am fine as long as I carry a plastic bag in my purse; that is enough to have saliva on the way..." [I-16]

e) "...I live in the hands of alternative medicine doctors because I trust them completely. I live in ozone treatments which elevated my immune system in a way that, when I got bacteremia I thought I wouldn't be back to work, and ozone helped a lot. That is amazing..." [I-2]

f) “...Quantum medicine to detox from asteroids and a different cellular response to external agents to diminish the ability for a pathological reaction... " [I-10]

* The alphanumeric code used for identifying the source of verbatim is: [I (means Interview)-number]

\section{Discussion}

The results of this study unveil perceptions of quality of life, general and oral health and its determinants in patients with Xerostomia, highlighting elements related to the social and economic context that impact on health conditions and the welfare of these people. Social support and social practices contribute to overcoming dry mouth. To the best of our knowledge, this is one of the few studies analyzing the research question from a qualitative perspective.

Although most studies of oral health related quality of life related focus on a quantitative approach, to know deeply the perceptions and opinions of the patients from a qualitative point to view is a priority to understand them. Main findings justify the necessity for health workers and students to comprehend the feelings and the expectations of patients suffering from Xerostomia, in order to provide the means necessary to face the disease in a better way. According to Bascones et al., dry mouth consequences are not limited only to physical signs and symptoms. An important part of people's daily life is affected since the disease produces insomnia, irritability, depression and these aspects influence the sociability of people suffering Xerostomia (Bascones et al., 2007). Social support provided by health professionals, NGOs and other organizations is very crucial to help people feel more secure, confident and valued in their social circles (family, friends, neighbors, etc.), with the aim of strengthening their life project.

One important result of this study is related to the fact that interviewed people say they have knowledge about the disease. It should be noted that knowledge of patients is linked to the relationship health team/patient/family. The acquisition of such knowledge is mediated by factors such as objectivity, systemic conception, historicism and transformative social practice, as well as the existing empathy among members of that relationship (González Menéndez, 2006). Nevertheless, when the research team asked the participants about oral health, some of them expressed ignorance of their status and this situation suggest a possible failure in counseling by health personnel or barriers to accessing general and oral health services, as related by patients (Hernández Bello \& Vega Romero, 2001). To improve access to the health system would mean access to the knowledge that the professional has on Xerostomia.

In close relationship with oral healthcare, respondents' discourses have allowed emergent categories related with 
barriers and facilitators to access health services in the context of the Social Security System in Colombia (Hernández Bello \& Vega Romero, 2001). It is pointed out that those who were satisfied with the service provided, were those who had the privilege of care, since they enjoyed a differentiated coverage of services in health, in contrast to the rest of the subjects. This situation indicates inequality and exclusion and is mentioned in the literature as "inverse care law", meaning that those with the greatest need of health care use the health services less, and less effectively, than do those with least need (Hart, 1971). Specifically, the barriers to the oral health care in people suffering Xerostomia is an example of this in the health system in Colombia, as evidenced by Molina in a qualitative study (Molina \& Ramírez, 2013), where main findings emphasize that health care is based on a renter management, which controls the demand for services, through administrative, geographic and economic barriers. Such strategies end up affecting the quality of health care.

Closely related to the above as manifested by patients is access to medicines. This research confirm the findings of Reveiz et al. (Reveiz et al., 2013), in a systematic review about right-to-health litigation in three Latin American countries. In this research was founded that the percentage of lawsuits related to access to medicines ranged between $11.9 \%$ and $35.4 \%$. Although the comprehensive and systematic attention is written as a Fundamental Right to Health, there exits continuous tensions with private insurance, and the patient become unprotected, preventing against quality health care hence affecting the dignity of the patient (Gañan, 2014).

Participants' responses provided definitions of quality of life, health and oral health that had coincidences with the proposals in literature. The study group of Quality of life of the World Health organization WHOQOL (The WHOQOL Group, 1995), established the concept of QL as: "Individuals perception of their position in life in the context of the culture and value systems in which they live and in relation to their goals, expectations, standards and concerns". Urzúa (Urzúa \& Caqueo-Urízar, 2012) developed a theoretical review about the QL concept and it has several definitions such as: "Personal welfare derived from satisfaction ...", "Meeting needs in physical, psychological and social areas, from material and structural activities", "Mathematical equation that represents the natural endowment of the patient, the contribution of the home and family and the contribution made by the society to the individual", "Satisfaction, happiness, fulfillment and ability to face situations", among others. Participants intuitively related QL to health, as well as with absence of disease and pain, to the ability to work and to the contribution that each one can make from their labor to society, in conditions of normality.

Subsequently, participants give value to QL in three categories such as good, fair or poor. In the first case, this classification is based on the fact that old age could bring health problems and they see their condition as normal. In other cases, people referred movement and displacement problems, presence of pain and polypharmacy. All this was reported in the majority of cases in relation to chronic diseases and also with the dimensions analyzed in different studies that investigate the perceived QL in adult patients (Ramírez, 2007).

One of the most relevant categories for study participants was the social support, which is considered as a multidimensional concept and it is referred to resources, aid or benefits that are provided to individuals (Castro, Campero, \& Hernández, 1997). Respondents perceived the support offered at a formal level from different institutions, organizations or support groups, as well as those arising from social relationships with family, friends and community. These resources of the environment promote social relations, and the adaptation and well-being of the individual for a better development in the social context. Social support constitutes a key element for improving the QL, and is expressed as feelings of personal comfort, satisfaction and good mood against the signs and symptoms of Xerostomia. These findings are consistent with previous studies where less isolated individuals, and those with better relations with the social environment, may have a better physical and mental health (Cohen, 2004; Matud, Carballeira, López, Marrero, \& Ibáñez, 2002). Furthermore, some gender differences could be observed. Since stereotype of women implies warmth, expressiveness, and comfort with intimacy, they are more willing to acknowledge the difficulties and seek help from others (Matud et al., 2002; Vaux, 1985), whereas male, are more related with autonomy, self-confidence and independence. It is important to emphasize that 21 of participants were female.

It should be made clear which are the strengths of this study. Qualitative research enables the recognition of opinions and perceptions about the phenomena that affect the oral health status and quality of life of the population suffering Xerostomia, transcending restrictive biomedical views of health and disease. The conceptual framework and the main categories from the participants' discourses found in this study were validated with the target population through the focus group. At the same time social return of main findings was possible through educational strategies. However, in interpreting the results, it is important to take the study's limitations into account. Information for this research was obtained mainly from women and only one man could be interviewed, due to difficulties in the field to access them. However, according to epidemiological data, Xerostomia affect mainly females hence, it is expected that additional and the main points of view were collected. 
Further research could be focused on male by means of establishing contact with other Organizations and support institutions. Lastly, although the aim of qualitative research by nature is not to generalize the results, it seems important to recognize the need to use quantitative methods in order to offer possible epidemiological associations and complement the results in this study.

\section{Conclusions}

Addressing oral health problems in patients affected with Xerostomia requires multidisciplinary actions that recognize the patient as a subject with different expectations, needs and interests. Also, reinforcing communication between health providers and patients is an effective measure that strengthens the educational activities, because awareness is gained about the characteristics of the disease and patients would be more pleased to have an important social support. Similarly, reducing inequalities in health status involves social policies that contribute to improving the quality of life and ensure the welfare of citizens by means of improving access to health services with quality and efficiency.

\section{Authors' Contributions}

All the authors contributed to the design of the study. KRS, AMP, DZV \& KVG participated to data collection and compilation. KRS, AMP, DZV \& KVG conducted the data analysis, with the supervision of APL \& AAAS, and all the authors participated in data interpretation. All the authors have revised the different drafts of the paper and have approved the final version. All the authors had full access to all of the data in the study and assume responsibility for the integrity of the data and the accuracy of the data analysis.

\section{Acknowledgments}

We would like to thank the study participants to share their experiences with us.

\section{Conflict of Interest}

The authors declare that there is no conflict of interests regarding the publication of this paper.

\section{References}

Al-Dwairi, Z., \& Lynch, E. (2014). Xerostomia in complete denture wearers: Prevalence, clinical findings and impact on oral functions. Gerodontology, 31(1), 49-55. http://dx.doi.org/10.1111/ger.12002

Allen, P. F. (2003). Assessment of oral health related quality of life. Health Qual Life Outcomes, 1, 40. http://dx.doi.org/10.1186/1477-7525-1-40

Ami, S., \& Wolff, A. (2010). Implant-Supported Electrostimulating Device to Treat Xerostomia: A Preliminary Study. Clin Implant Dent Relat Res, 12(1), 62-71. http://dx.doi.org/10.1111/j.1708-8208.2009.00180.x

Anil, S., Vellappally, S., Hashem, M., Preethanath, R. S., Patil, S., \& Samaranayake, L. P. (2016). Xerostomia in geriatric patients: A burgeoning global concern. $J$ Investig Clin Dent, 7(1), 5-12. http://dx.doi.org/10.1111/jicd.12120

Bascones, A., Tenovuo, J., Ship, J., Turner, M., Mac-Veigh, I., López-Ibor, J., . . . Aliaga, A. (2007). Conclusiones del Simposium 2007 de la Sociedad Española de Medicina Oral sobre "Xerostomía. Síndrome de Boca Seca. Boca Ardiente". [Conclusions of 2007 Symposium by the Spanish Society of Oral Medicine; on "Xerostomia. Dry Mouth Syndrome. Burning Mouth"]. Av Odontoestomatol, 23(3), 119-126. http://dx.doi.org/10.4321/S0213-12852007000300002

Benn, A. M., Broadbent, J. M., \& Thomson, W. M. (2015). Occurrence and impact of xerostomia among dentate adult New Zealanders: findings from a national survey. Aust Dent J, 60(3), 362-367. http://dx.doi.org/ 10.1111/adj.12238

Castro, R., Campero, L., \& Hernández, B. (1997). La investigación sobre apoyo social en salud: Situación actual y nuevos desafíos. [Research on social support and health: Current status and new challenges]. Rev. Saúde Pública, 31(4), 425-435. http://dx.doi.org/10.1590/s0034-89101997000400012

Chapa, A., Garza, S., Garza, E., \& Martínez, S. (2012). Hiposalivación y xerostomía; diagnóstico, modalidades de tratamiento en la actualidad: Aplicación de neuroelectroestimulación. [Hyposalivation and xerostomia. Diagnosis, current treatment modalities: Application of neurostimulation]. Rev Mex Periodontol, 3(1), $38-46$.

Cohen, S. (2004). Social relationships and health. Am Psychol, 59(8), 676-684. http://dx.doi.org/10.1037/0003066X.59.8.676

Coimbra, F. (2009). Xerostomia. Etiologia e Tratamento. [Xerostomia. Etiology and treatment]. Rev Port 
Estomatol Med Dentária e Cir Maxilofac, 50(3), 159-164. http://dx.doi.org/10.1016/s16462890(09)70117-7

Enoki, K., Matsuda, K.-i., Ikebe, K., Murai, S., Yoshida, M., Maeda, Y., \& Thomson, W. M. (2014). Influence of xerostomia on oral health-related quality of life in the elderly: A 5-year longitudinal study. Oral Surg Oral Med Oral Pathol Oral Radiol, 117(6), 716-721. http://dx.doi.org/10.1016/j.oooo.2014.03.001

Gañan, J. (2014). Fundamental rights (derecho a la salud) y business, caso Colombia y Latinoamérica. [Fundamental Rights (right to health) and business. The Latin American and Colombia cases]. Bruno Amaro Lacerda, 17(2), 22-40.

González Menéndez, R. (2006). La relación equipo de salud-paciente-familiar. Rev Cubana de Salud Pública, 32(3).

Hahnel, S., Schwarz, S., Zeman, F., Schafer, L., \& Behr, M. (2014). Prevalence of xerostomia and hyposalivation and their association with quality of life in elderly patients in dependence on dental status and prosthetic rehabilitation: A pilot study. J Dent, 42(6), 664-670. http://dx.doi.org/10.1016/j.jdent.2014.03.003

Hart, J. T. (1971). The inverse care law. Lancet, 1(7696), 405-412. http://dx.doi.org/10.1016/S01406736(71)92410-X

Hernández Bello, A., \& Vega Romero, R. (2001). El sistema colombiano de seguridad social en salud: desigualdad y exclusión. [The colombian system of social security in health: inequality and exclusion]. Rev Gerenc Polit Salud, 1(1), 48-73

Ibáñez, N., López, C., \& Piña, B. (2009). Frecuencia de hiposalivación (Xerostomía) en pacientes geriátricos. [Prevalence of hyposalivation (Xerostomia) in geriatric patients]. Rev. $A D M, 65(5), 56-60$.

Ikebe, K., Matsuda, K.-i., Morii, K., Wada, M., Hazeyama, T., Nokubi, T., \& Ettinger, R. L. (2007). Impact of dry mouth and hyposalivation on oral health-related quality of life of elderly Japanese. Oral Surg Oral MedOral Pathol Oral Radiol Endod, 103(2), 216-222. http://dx.doi.org/10.1016/j.tripleo.2005.12.001

Kaluzny, J., Wierzbicka, M., Nogala, H., Milecki, P., \& Kopec, T. (2014). Radiotherapy induced xerostomia: mechanisms, diagnostics, prevention and treatment--evidence based up to 2013. Otolaryngol Pol, 68(1), 1-14. http://dx.doi.org/10.1016/j.otpol.2013.09.002

Lee, E., Lee, Y.-H., Kim, W., \& Kho, H.-S. (2014). Self-reported prevalence and severity of xerostomia and its related conditions in individuals attending hospital for general health examinations. Int J Oral Maxillofac Surg, 43(4), 498-505. http://dx.doi.org/10.1016/j.ijom.2013.10.011

Liu, B., Dion, M. R., Jurasic, M. M., Gibson, G., \& Jones, J. A. (2012). Xerostomia and salivary hypofunction in vulnerable elders: Prevalence and etiology. Oral Surg Oral Med Oral Pathol Oral Radiol, 114(1), 52-60. http://dx.doi.org/10.1016/j.oooo.2011.11.014

Loyo Molina, K., Balda Zavarce, R., González Blanco, O., Solórzano Peláez, A. L., \& González, A. (1999). Actividad cariogénica y su relación con el flujo salival y la capacidad amortiguadora de la saliva.[Cariogenic activity and its relationship with the salivary flow and the buffer capacity of saliva]. Acta odontol. venez, 37(3), 10-17.

Masood, M., Masood, Y., \& Newton, T. J. (2010). Methods of qualitative research in dentistry: A review. Dent Update, 37(5), 326-328, 331-322, 334-326.

Matud, P., Carballeira, M., López, M., Marrero, R., \& Ibáñez, I. (2002). Apoyo social y salud: Un análisis de género. [Social support and health: A gender analysis]. Salud mental, 25(2), 32-37.

Misrachi, C., \& Espinoza, I. (2005). Utilidad de las Mediciones de la Calidad de Vida Relacionada con la Salud. [Usefulness of quality of life related to health measurements]. Rev. Dental de Chile, 96(2), 28-36.

Molina, G., \& Ramírez, A. (2013). Conflicto de valores en el sistema de salud de Colombia: entre la economía de mercado y la normativa constitucional, 2007-2009. [Conflicting values in Colombia's health system: balancing the market economy and constitutional legislation, 2007-2009]. Rev Panam Salud Publica, 33(4), 287-293. http://dx.doi.org/10.1590/S1020-49892013000400008

Oh, D.-J., Lee, J.-Y., Kim, Y.-K., \& Kho, H.-S. (2008). Effects of carboxymethylcellulose (CMC)-based artificial saliva in patients with xerostomia. Int $J$ Oral Maxillofac Surg, 37(11), 1027-1031. http://dx.doi.org/10.1016/j.ijom.2008.06.006

Ramírez, R. (2007). Calidad de vida relacionada con la salud como medida de resultados en salud: Revisión 
sistemática de la literatura. [Quality of life as a measure correlated to health outcomes: systematic revision of literature]. Rev Colomb Cardiol, 14(4), 207-222.

Reveiz, L., Chapman, E., Torres, R., Fitzgerald, J. F., Mendoza, A., Bolis, M., \& Salgado, O. (2013). Litigios por derecho a la salud en tres países de América Latina: revisión sistemática de la literatura. [[Right-to-health litigation in three Latin American countries: A systematic literature review]. Rev Panam Salud Publica, 33(3), 213-222. http://dx.doi.org/10.1590/s1020-49892013000300008

Stewart, C. M., Berg, K. M., Cha, S., \& Reeves, W. H. (2008). Salivary dysfunction and quality of life in Sjogren syndrome: A critical oral-systemic connection. J Am Dent Assoc, 139(3), 291-299; quiz 358-299. http://dx.doi.org/10.14219/jada.archive.2008.0158

Stewart, K., Gill, P., Chadwick, B., \& Treasure, E. (2008). Qualitative research in dentistry. Br Dent J, 204(5), 235-239. http://dx.doi.org/10.1038/bdj.2008.149

Strietzel, F. P., Martin-Granizo, R., Fedele, S., Lo Russo, L., Mignogna, M., Reichart, P. A., \& Wolff, A. (2007). Electrostimulating device in the management of xerostomia. Oral Dis, 13(2), 206-213. http://dx.doi.org/10.1111/j.1601-0825.2006.01268.x

The WHOQOL Group. (1995). The World Health Organization Quality of Life assessment (WHOQOL): Position paper from the World Health Organization. Soc Sci Med, 41(10), 1403-1409. http://dx.doi.org/10.1016/0277-9536(95)00112-K

Urzúa, A., \& Caqueo-Urízar, A. (2012). Calidad de vida: Una revisión teórica del concepto. [Quality of life: A theoretical review]. Ter Psicol, 30(1), 61-71. http://dx.doi.org/10.4067/s0718-48082012000100006

Vaux, A. (1985). Variations in social support associated with gender, ethnicity, and age. J Soc Issues, 4l(1), 89-110. http://dx.doi.org/10.1111/j.1540-4560.1985.tb01118.x

Villa, A., Connell, C. L., \& Abati, S. (2015). Diagnosis and management of xerostomia and hyposalivation. Ther Clin Risk Manag, 11, 45-51. http://dx.doi.org/10.2147/TCRM.S76282

\section{Copyrights}

Copyright for this article is retained by the author(s), with first publication rights granted to the journal.

This is an open-access article distributed under the terms and conditions of the Creative Commons Attribution license (http://creativecommons.org/licenses/by/3.0/). 